OPEN ACCESS

Edited by:

Kristiina Kumpulainen, University of Helsinki, Finland

Reviewed by: Maria Beatrice Ligorio, University of Bari Aldo Moro, Italy Allen Leung, Hong Kong Baptist University, Hong Kong

*Correspondence: Lindsay Lindberg lindsay.lindberg@ucla.edu

Specialty section: This article was submitted to STEM Education, a section of the journal Frontiers in Education

Received: 25 February 2020 Accepted: 14 April 2020 Published: 15 May 2020

Citation: Lindberg $L$, Fields $D A$ and Kafai YB (2020) STEAM Maker

Education: Conceal/Reveal of Personal, Artistic and Computational Dimensions in High School Student Projects. Front. Educ. 5:51. doi: 10.3389/feduc.2020.00051

\section{STEAM Maker Education: Conceal/Reveal of Personal, Artistic and Computational Dimensions in High School Student Projects}

\author{
Lindsay Lindberg $^{1 *}$, Deborah Ann Fields ${ }^{2}$ and Yasmin B. Kafai ${ }^{3}$ \\ 1 Graduate School of Education and Information Studies, University of California, Los Angeles, Los Angeles, CA, \\ United States, ${ }^{2}$ College of Education and Human Services, Utah State University, Logan, UT, United States, ${ }^{3}$ Graduate \\ School of Education, University of Pennsylvania, Philadelphia, PA, United States
}

Much of maker education's expansion has focused on STEM (science, technology, engineering, mathematics) learning, leaving out equally promising opportunities for integrating arts learning. In this paper we share findings from a project in which high school students created electronic-textiles-based art representing features of a community important to them as a part of an elective high school computer science class. We addressed the following research questions: (1) What kinds of personal and community meanings did students convey through their maker projects? (2) How did students engage with artistic dimensions in their projects? (3) How did coding interactive features support students' artwork? Drawing on daily observations, pre/post interviews, and documentation of students' artifacts (photographs of in-process designs, design notebooks, and artist statements), we developed four case studies of students as they made art representing their communities using electronic-textiles as their primary medium. Our findings reveal how making became a means of personal, artistic expression with quite literal layering of coded meanings, and how maker activities can integrate art. In the discussion we consider the opportunities for authentic artistic expression in maker education by distinguishing the difference between craft and art in a maker education context. We consider the ways in which these ideas have implications for equity, pedagogy, and future research.

Keywords: maker education, e-textiles, STEAM, computer science education, art education

\section{INTRODUCTION}

Much of the popularity of the maker movement has been fueled by its promise of preparing the next generation of innovators by turning students from consumers into designers of technology (Honey and Kanter, 2013). Started initially in out-of-school spaces such as community centers, public libraries, and science museums (Sheridan et al., 2014), there is now a growing interest in bringing maker spaces and activities into K-12 classrooms (Peppler et al., 2016a,b). This transition into schools comes with considerable challenges as maker education has promoted interest-driven 
and open-ended learning that stands in stark contrast to the timeconstrained and curriculum-driven nature of most classroom activities. Furthermore, the distributed expertise and flexible collaborative arrangements present in many makerspaces are difficult to replicate in classrooms with only one teacher present and a focus on individual accomplishments.

An even more pressing challenge has been maker education's nearly exclusive focus on STEM (science, technology, engineering, mathematics) topics and specific applications amplifying the lack of diversity and already existing equity issues present in many STEM fields. Critics of maker activities (e.g., Vossoughi et al., 2016; Barton and Tan, 2019) have argued that a predominant focus on hi-tech rockets, robots, and drones (see Buechley et al., 2013b) leaves out other equally relevant maker applications with electronics that include lo-tech materials such as textiles, paper, and wood, leverage traditional crafts such as sewing and weaving, and connect to arts education. Customizations of electronics for textile- and paper-based maker applications have been shown to significantly broaden who is participating and what is being made (Buechley et al., 2013a; Qi et al., 2018). Furthermore, expanding STEM's focus to include arts and design can not only promote technical skills valued in STEM but also engage students in critical inquiry (Hetland et al., 2013). But so far, there have been few examples (e.g., Litts et al., 2019) that illustrate the potential of STEM + Art or STEAM (Science, Technology, Engineering, Arts, and Mathematics) (Maeda, 2013) approaches for K-12 maker education.

In this paper we investigated STEAM maker activities which leverage lo-tech materials and traditional crafting practices in the context of arts and computing education. We designed a series of activities for high school students to engage with using tools that afforded opportunities to integrate computation with art and design during the school day. From the computing side, we used electronic textiles (Buechley et al., 2013a) that combine the stitching of electronic circuits with conductive thread to connect microcontrollers to LED actuators and sensors, while from the arts side we brought in design directives, audience considerations and artist statements to frame the maker activities (Eisner, 2002; Hetland et al., 2013). Together they resulted in students making art, integrating electronics and other digital elements into artwork with the goal to represent, reimagine, and reflect on personal and cultural connections. More specifically, students worked on Conceal/Reveal, a project directive that invited them to consider a community meaningful to oneself, and then reveal something about that community that was generally concealed or invisible to outsiders. Over the course of 3 months, students chose, drew, or painted images that were printed onto stretched canvases, then stitched and coded LEDs and sensors to generate lighting, music, and interactive effects.

Drawing on observations, interviews, and artifacts, we developed four case studies of students as maker-artists to address the following research questions: (1) What kinds of personal and community meanings did students convey in their maker artifact? (2) In what ways were the artifacts created by the students computational art? (3) How did the medium of electronic textiles (hereafter: e-textiles), and the process of "making" inherent in creating e-textiles, support students' artwork? Our findings reveal how making became a means of personal expression with quite literal layering of coded meanings, how this e-textilesbased maker activity integrated elements of art, and how the computational medium of e-textiles helped to produce expressive computer science (hereafter: CS) artifacts which were not only personally relevant, but also rich in computational content and communication. In the discussion we consider the opportunities for authentic artistic expression in maker education, with implications for equity, pedagogy, and future research.

\section{BACKGROUND}

\section{From STEM to STEAM}

The maker movement at its core is driven by people making artifacts. This can be motivated by a wide variety of impulses including the pursuit of curiosity, engagement, pleasure, or an interest in creating objects with particular functions. There is also a commonly held assumption that making can be a democratic act, in that any person can make, innovate, or create artifacts which will impact the world (Dougherty, 2012; Hatch, 2014; Halverson and Sheridan, 2014). The relatively recent popularity of the maker movement can be tied to the proliferation of technology, and the ability to share ideas and strategies virtually (Anderson, 2012). And while making is not solely rooted in the development of new, smaller, easily accessible technologies, there is an affiliation between the use of technology and tools and maker spaces (Hatch, 2014; Halverson and Sheridan, 2014; Martin, 2015). The maker movement, initially popularized by hobbyists in their homes, or maker studios in informal learning environments, has begun to move into more formal school settings, with the hopes of promoting interest-driven, openended learning in formal classrooms.

As maker education is expanding from strictly informal learning settings to sites of formal learning (Blikstein, 2013; Halverson and Sheridan, 2014; Cohen et al., 2017), the curricular emphasis has been on STEM learning (Hsu et al., 2017). The connection between maker education and STEM learning can be traced back to efforts to make the United States more globally competitive (National Research Council, 1999) by preparing young people to be technologically literate and able to enter the STEM workforce. This emphasis has permeated all aspects of K-12 maker education, linking increased participation in STEM fields with building 21st century skills (Katehi et al., 2009; Smith, 2016; Taylor, 2016; Litts et al., 2017). As a result, the vast majority of maker activities are grounded in STEM or CS contexts (Martin, 2015) with an emphasis on students learning how to control-or program-tools such as $3 \mathrm{D}$ printers, laser cutters and microcontrollers to create personally meaningful artifacts and applications (Blikstein and Worsley, 2016; Peppler et al., 2016a,b).

In expanding the curricular emphasis and location of maker activities, there has been a growing interest in including the arts, and moving from STEM to STEAM. Indeed, educators, researchers, and policy makers across the globe have noted the opportunity presented by integrating learning content from 
different disciplines into a single project—often with "the arts acting as a significant fulcrum through which wider domain learning and creativity is promoted" (Harris and de Bruin, 2018, p. 167). Just like their STEM counterparts, proponents argue that "art and design are poised to transform our economy in the 21st century like science and technology did in the last century, and the STEAM movement is an opportunity for America to sustain its role as innovator of the world" (p. 2, Maeda, 2013).

With technologies more accessible and affordable, artists have begun using computational arts to engage in creative and critical inquiry both as process and product. In fact, the popular open-source hardware and software system for microcontrollers, Arduino, was designed by and for designers, to support artists in creating tangible, interactive designs (Banzi, 2011; Przybylla and Romeike, 2014). With artists capitalizing on the capacity to integrate microcontrollers and computational elements into visual art to further their creative practice, we argue that the reverse is also true-that there are benefits for integrating art elements into computational practices and projects. In arts activities, the artifact or art piece is often layered with multiple media and techniques, and regularly includes personally meaningful, representational, or expressive content (Eisner, 2002). Maker activities are often rooted in a set of practices that promote iteration, creative or novel uses of materials and tools, and a do-it-yourself mindset which values the making process as essential to the learning (Honey and Kanter, 2013; Peppler and Bender, 2013; Halverson and Sheridan, 2014; Sheridan et al., 2014). Connecting the two would allow makers to engage in richer ways with artifact production by using a wider variety of materials and forms of representations and reflections (Hetland et al., 2013). Research has shown that this kind of participation in the arts can also promote participation in STEM (Peppler and Wohlwend, 2018), leading to meaningful engagement with both STEM and art learning.

Despite a broad interest in STEAM education, this is a relatively recent development in educational research (Gadsen, 2008), and there is often confusion about what is meant by the " $A$ " in STEAM - with authors considering visual art, dance, theater, music, digital media arts, and others each art disciplines in and of themselves worthy of integrating with STEM learning (Colucci-Gray et al., 2017). This undefined nature of "STEAM" has important implications in understanding the ways in which art and the arts are defined and implemented in formal learning contexts. In this study, we argue that incorporating pedagogical strategies informed by art education contribute to the developing field of STEAM education.

But so far few STEAM maker projects have leveraged artsbased practices. One exception is the work of Litts et al. (2019) who developed a "maker studio" model integrating various forms of social critiques by peers and teachers that are commonly utilized in art classes (Hetland et al., 2013). They observed, just like in art classes, these forms of reviews, scheduled throughout the project, helped students develop designs, address technical issues, and learn how to explain their process of design. However, social critiques are only one aspect of art studio practices that can shape a maker studio model. In this paper, we further develop the maker studio model by including design directives related to artistic intent, considerations of audience, and iterative, processoriented reflection. Each of these characteristics are based in arts education. The intentional development of personally meaningful artifacts is an important element in art education (Gnezda, 2009) that plays a role in distinguishing making from art. While an artifact might be technically well made and carefully designed, without personal intent behind the project, it remains a well-made maker artifact, not a piece of student made computational art.

Further, art often takes into consideration the intended audience. Consideration of audience can bring a project from personal artifact with personal meaning to a piece with representative, cultural meaning for viewers beyond the designer. This is an important step in developing student voice, and building a connection with a viewership (e.g., Greene, 1995; Magnifico, 2010; Halverson, 2013; Hetland et al., 2013). Finally, another important element of arts education is the distinction between the creative process and the creative product (Fiske, 1999; Eisner, 2002). In K-12 arts education there can be an overemphasis on the final product to be representational or align with a certain aesthetic (Efland, 1990; Gude, 2013). Instead of a single focus on the product, iterative, process-oriented design and making should be valued. In the Conceal/Reveal project, we structured consideration of intent, audience, and iterative design reflections throughout the design of the project in the context of electronic textiles, a relatively new domain of making that involves soft crafts.

\section{Electronic Textiles for STEAM}

Electronic textiles combine hi-tech approaches from engineering and computing with lo-tech materials like textiles and thread and traditional crafting practices of sewing and embroidery (Buechley, 2006). In e-textiles, students stitch circuits with conductive thread to connect and control actuators such as LEDs and loudspeakers, and sensors such as light, sound, and touch with a microcontroller to produce interactive art displays and functional wearables (Buechley et al., 2013b).

E-textiles have all the markings of a typical maker activity by including electronics, sensors and actuators but they also broaden traditional making by including textiles and crafting practices. E-textiles have the potential to support personalized, disruptive designs for traditionally marginalized individuals in STEM (Kafai et al., 2014; Searle et al., 2016) thus addressing key criticisms leveled against maker education. Making has been criticized as being a predominately white field of both learners and educators while also promoting a limited range of maker activities in electronics (Buechley et al., 2013b; Barton et al., 2016; Fields et al., 2018). Like Vossoughi et al. (2016), researchers have argued for expanded notions of making to also attend to "sociopolitical values and purposes of making." E-textiles as a set of practices and media provides opportunities to connect relevant student concerns with learning STEM content. For example, this has been evidenced by researchers (Barton et al., 2016) who report students in an afterschool maker space designing and making an "anti-rape jacket" (Barton et al., 2016, p. 15) - a sweatshirt that has bright LEDs, and produces a loud alarm that can be heard one block away 
when the wearer stamps their foot and perceives danger. This project was conceptualized based on the participants' real concerns about safety during commuting, and walking alone on dark streets, and uses e-textiles to solve a culturally relevant problem for the designers using computational elements to address the issue. The "anti-rape jacket" demonstrates the possibility of addressing culturally relevant community concerns with computational, maker-based solutions, but many of these projects have lacked sophisticated designs, privileging the functionality over aesthetics-a missed opportunity for learning by bypassing engagement with the arts.

While e-textiles expand the repertoire of maker projects in materials and practices, they have been limited in the ways they promote computing. A recent synthesis of research on e-textiles conducted with thousands of students in and out of schools during the last decade revealed that the majority of applications involved simple circuit designs (Jayathirtha and Kafai, 2019) not realizing this e-textiles' potential for computing. While the research also demonstrated that students' perspectives on computer science broadened, relatively few studies used e-textiles to introduce computational concepts and practices that went beyond basic sequences or simple conditionals. One example of a project that did go further in computational concepts and practices is the Stitching the Loop unit (Kafai et al., 2019), part of a year-long introductory course into Exploring Computer Science (Goode et al., 2012). In this e-textile curriculum unit, students created a sequence of increasingly complex e-textile projects that were personal and also involved using more sophisticated computational concepts and practices (e.g., multiple conditionals, operators, sensing, data, etc.). However, there are many other ways to expand into more sophisticated computational concepts in areas that might fit well with artistic expression, particularly in coding sound and in exploring interactive effects with sensors.

\section{Expanding E-textiles Into Computational Art}

Art can be defined in many ways-as a system of production, communication, or reflection (Pearse, 1983; Rolling, 2008). As humans find ways to make meaning of their surroundings (Dissanayake, 2003), there is a broad spectrum and long history of who has the authority to name artifacts as "Art" and whose work is valued as "Art." In this study we consider how a STEAM-based approach can expand how we think about maker artifact creation by leveraging personal interests and community connections through maker education in a school classroom. By promoting art as making, we expand the maker studio model (Litts et al., 2019) by foregrounding visual art and aesthetic practices that link together artifact, audience and artist. For one, we examined how design directives from the arts could extend the personalized meaning of maker artifacts that has dominated much of maker education. In arts and design education, design directives provide constraints while still giving room for exploration.

In our case, we focused on tensions between an individual and community. More specifically, students worked on Conceal/Reveal, a directive that asked them to represent a community meaningful to oneself, and then reveal something about that community that was generally concealed or invisible to outsiders. Having students intentionally incorporate elements of their lived experiences into an artifact has the potential to deepen learning outcomes and connect students to issues larger than themselves (Taylor and Sobel, 2011; Lai, 2012), allowing a personalized craft to perhaps become personalized art. This approach does not claim that designing a reflective, personally meaningful learning environment produces an artist, or even an artwork. Rather, we argue that incorporating pedagogical strategies informed by art education (Hetland et al., 2013), including design directives, reflective practices, consideration of audience, iteration and articulation of artistic perspectives from the young people involved, provides rich learning opportunities. These practices can deepen students' engagement with content and support the development of the self in a formal CS learning environment. This approach contributes to the developing field of STEAM pedagogical strategies and philosophical perspectives of art in STEM education around the world.

Furthermore, audience considerations are a critical element in any arts project. In our case, we thought to enhance audience interactions by promoting programming of visual and musical elements as responses to interactive inputs that would engage students in more complex computational concepts of data and control structures. Here we build on a mutually beneficial relationship that can exist between fostering learning of computational concepts and enhancing aesthetic dimensions. Designing for interactivity is not simply technical: it also includes consideration of the audience when designers think about how they want their audience to interact with their artwork or what reactions or feelings they want to promote. Most previous e-textile designs that include an interactive element such as a switch favor interaction simply in terms of usability or as a means of providing scientific information (e.g., Olsen et al., 2018). Most also include only one type of output: turning lights on and off (e.g., Kafai et al., 2019). By expanding from visual to include aural or musical feedback in response to audience interaction with the artifact, the Conceal/Reveal directive moves student makers into more complex territory.

We also designed reflective prompts for the students to engage with during the design process including, "What types of interaction can you design? How can you make people act?" and, "How do you want people to feel when they interact with your design?" Beginning with the embodied human interaction component (what is your goal as a designer to inspire a viewer do and feel), rather than only considering the possibilities afforded by the microcontroller (light, temperature, or sound sensor), provides space for participants to make socially meaningful connections to their lived experiences, articulate their design intentions, and consider the future viewers of their computational art. By including a more sophisticated call to consider audience emotions in interactivity, the Conceal/Reveal directive shifts an e-textiles craft toward more socially meaningful e-textiles art.

Finally, artist statements add both an expressive and reflective dimension to artifacts that explain intent and process. Here we build on prior work in which students created portfolios that documented design processes, challenges and solutions 
of their e-textile projects and thus engaged in computational communication-a computational thinking practice that not only showcased their understanding of technical language and concepts (Lui et al., 2016) but also made explicit personal connections (Shaw et al., 2019). However, while maker portfolios such as these focus on process and product, they rarely engage the designer with an audience that contributes to "equitably consequential learning" that is "always linked to individual and social histories that unfold across space and time" (Barton et al., 2016). Artist statements and personal reflections on intent behind the design process deepen these types of reflections toward artistic communication. By allowing written reflection on the design process, artist statements provide a space for students to describe how their design choices helped express their community participation. We now turn to describing the methods used for this project, a detailed description of the Conceal/Reveal design directive, and findings that demonstrate the ways students leveraged expression and personal intent to create meaningful, computationally complex computational art projects.

\section{MATERIALS AND METHODS}

For this project, the authors designed and implemented a 13week curricular project integrating an e-textile maker-based project with complex CS content and elements of visual art. Ethnographic methods (Saldaña, 2015) of data collection were used in order to capture students' designs, meaning-making, and learning processes within the project.

\section{School and Participants}

This unit took place at a public high school ( $~ 700$ students) in a large metropolitan area on the west coast of the United States, as part of a class called "Generative Arts and Design" that covered computation and art approaches. This was a brand new course intended to be the second course in a three-year computing track in Career and Technical Education. However, most of the students did not have previous coding experience, and were novices to making computational artifacts. The teacher had one prior year of experience with electronic textiles from an earlier study (see Kafai et al., 2019) and, as a result of that experience, invited the research team to help her create a different e-textiles unit for her new Generative Arts and Design course. She requested that the researchers teach the unit, which they did 4 out of 5 days a week. One researcher/teacher (Lindberg) is a professional art and dance educator (10 years of experience); the other researcher/teacher (Fields) has 10 years of experience developing and teaching e-textile projects to students and teachers. These two researcher/teachers took turns leading the instructional Conceal/Reveal unit alongside the classroom teacher who was present at all times.

The school is a public high school with a predominantly Latinx/Hispanic population (86\%) with 2-5\% each of Filipino, African American, Caucasian, and Asian students. It is a Title 1 school because $78.8 \%$ of the students qualify for free or reduced lunch, and $42 \%$ of the students are English language learners.
The participating classroom included 26 high school students, with 10 female and 16 male students in grades 10-12 (21 agreed to participate in the study through signed student assent and parent consent forms). Some of the students chose to take the course and others were assigned by school counselors. About half of the students had a prior computing class from the year before (e.g., Exploring Computer Science) while the other half had no prior computing experience. The e-textiles unit was the second unit of the course, following a unit on Processing focused on creating geometric patterns using basic shapes and colors.

\section{Maker Curriculum: Conceal/Reveal Community Art}

The challenge in this maker-art unit was to represent a community meaningful to oneself, and then reveal something about that community that was generally concealed or invisible to outsiders, using e-textiles as a medium. This unit was developed in accordance with ideas common in arts education which says that both personal relevance and technical skills are important factors for learning in and through the arts (Fiske, 1999; Ellen and Stéphan, 2013; Winner et al., 2013), and the constraints (requirements) of the project (Hetland et al., 2013) pertained to both of these elements.

The materials of the project included canvas fabric with a printed image of choice on it, eventually stretched across a wooden frame for hanging in the classroom. Students layered lights, microcontrollers (the Adafruit Circuit Playground), conductive thread, and assorted craft materials to augment the canvas backdrop. They used the microcontroller's buzzer and sensors to code and create a sound or musical effect as well as an interaction effect for the project. Combined, the students used a number of regular materials (e.g., fabric, thread, markers, etc.), conductive/computational materials (e.g., LEDs, conductive thread, sewable microcontroller with sensors and sound buzzer) and coded effects (e.g., lighting patterns, sensing of light and sound, and music) to achieve interactive designs that combined material and virtual aspects.

The Conceal/Reveal project was the primary focus of a curricular unit that used a number of individual and classroom reflective prompts, design critique sessions, content lessons, and activities to support students in their designs. The unit began with written reflections and concept maps where students considered communities that were important to them, chose one, and created an image that represented that community either through a drawing, painting, digital design, or photograph. These visuals were converted to digital photographs and printed on fabric (via a print company) of a size to fit on a $16 \times 16$ inch wood frame.

In the 2 weeks that the images took to be printed onto fabric, the unit focused on two small-scale projects, in which the students designed personal "logos" to represent communities they participate in. These projects were designed to scaffold students' computational knowledge (polarity, basic circuitry), and familiarity iterating designs and using elements of visual art to represent personally meaningful elements of their lives with different kinds of media. After identifying a community, students designed a simple "logo" to represent it using geometric shapes 
and one LED, and made this into a paper circuit using copper tape and one LED. Next, students iterated on their first logo design, and using a battery, conductive thread, 3 colored LEDs, and colored felt, they designed and crafted their first e-textile of the unit - a felt logo utilizing meaningful symbolism, a distinctive design, and no lettering to represent their community. Many students used their "logo" projects as precursors to their larger Conceal/Reveal project, and represented the same community in both projects.

When the students' images had been printed onto canvas and delivered, students continued their design process. They considered where they wanted LEDs, created a circuit diagram, and sewed on the lights, often using other materials such as felt to add further layers to the lights or to create battery holders for the microcontroller. This aspect of the unit included various activities and lessons on computational circuit design, sewing tips, and feedback from the teacher on proposed diagrams. Next, students learned how to code lighting sequences in Arduino, making their LEDs blink in various patterns. Then students were introduced to other elements of coding including how to code basic musical notes with varying durations, how to transfer written music to coded music, and how to read sensors in order to create interaction effects. Coding interactions involved lessons on sensing light and sound, and programming lights and music within conditions created from the sensing. Students' designs grew and changed throughout the 3 -month design process as they developed new knowledge, learned the affordances and constraints of e-textiles materials and code, and gave and received feedback from their teacher, the researchers, and their peers on their designs. Throughout this process students were encouraged to write reflections in design notebooks on how they felt (multiple times a week), what they wanted their audience to perceive and feel, and what challenges arose during their project. In the final stage they stretched and stapled their canvas onto a frame and wrote a formal artist statement about the intentions behind the project and what it meant to them.

In order for the project to take place within a computer science and art course, it had to support learning a number of electronic, computational, and artistic concepts and techniques. The electronic concepts included polarity, circuitry (simple, parallel, computational), and troubleshooting circuitry. Computational concepts included basic sequences (lighting and music patterns), variables and functions (for storing data and lighting patterns), arrays (for coordinating musical tones and durations), conditionals and operators (for "if/else" statement based on various ranges of sensor readings), "for loops" (for fading effects of lights or playing music), and debugging code. The artistic concepts included some visual art concepts (color, contrast, balance, design, etc.), consideration of audience (e.g., "how do you want the viewers to feel when they interact with your project?"), and reflections on the design process, intent, and artist statements.

\section{Data Collection}

We used ethnographic methods of data collection to obtain different angles on students' design processes, with at least one researcher present 4 out of 5 days of the week during the entire unit (i.e., 4 times/week for 13 weeks). Observational data included a total of 39 written field notes ranging from 2 to 5 pages of single spaced type each (on the days when at least one researcher was present) focused on students' design processes: their ideas for their projects, changes and choices they made, and their struggles in making their projects. As part of the observations, researchers engaged regularly with students in short, ethnographic style interviews (Seidman, 2006) on the decisions, adjustments, edits, and revisions students made on their projects, recording this information in the field notes.

In addition we collected student artifacts, including regular photographs of students' projects (at least weekly, but generally daily) for a total of 789 photos, with 38-84 photos of each case study student's work, including scans of their complete design notebooks (including sketches, circuit diagrams, notes on code, and reflections on what their project meant to them). Pre and post surveys were collected via an online survey platform conducted during class time from all participating students. These provided background about their interests and competencies about computing and e-textiles.

Finally, we conducted pre and post interviews ranging on average from 18 to 25 minutes each with 14 of the 21 consented participants (in pairs) about their personal interests, backgrounds in computing and art, and the design of their projects. Preinterview questions allowed us to understand the students' previous experiences with CS, the arts, crafts, and their level of interest in these subjects. The pre-interview protocol also asked in what ways the students felt able to be creative in school and with computing, and asked for students to share their current career goals. Post-interview responses were also a key source of insight into the students' design processes, meaning-making, and final projects. Questions included, "how did you decide what to represent about yourself or your community?" Other questions inquired how the elements of the final design were impacted by the process-asking how the writing reflections, music choice, coding process, and lighting patterns affected their designs and how they thought about them. Students were also asked about the portion of the project they were most proud of, and what challenges they encountered throughout the process.

\section{Analysis}

In this study, we focused analysis on the design processes of students as they created their Conceal/Reveal projects. To do so we chose case study analysis (Yin, 2009), focusing on four focal participants. There were eleven consenting students for whom we had complete data sets (i.e., they participated in the pre- and postsurveys, pre- and post-interviews, attended class regularly, and completed all projects as part of the curriculum). From these, we sought students who represented a variety of levels of engagement and interest that demonstrated the range of participation in the project design: fully or peripherally engaged from the very beginning, high, low, or changing interest in computer science, great ease or great difficulty with coding various elements of the project. Priority was given to students from whom we had permission from both parents and participants, and consent to use anonymized photographs of their work and progress. In the end we selected gender-balanced focal students-two male and 
two female students-who demonstrated a variety of levels of interest and exhibited competence in CS. Each student had a unique perspective on and history with CS and Art.

Our case study analysis focuses on students' design processes and the meanings they made from their projects. For each student we organized all of the available data-including photographs, design notebooks, interviews, surveys, project documentation, assignments (i.e., "I am" poems, in-progress portfolios), and relevant sections of observations-into individual folders. Then we created detailed documentation of their design processes as well as the many layers of meaning making in their projects. For each of the four students, we then traced personal design choices throughout their design process, identifying all of the component parts of the project and the choices made within each area. This included community identification, visual representation of a community or activity for the background of the mural, placement of the Circuit Playground microcontroller, placement and color of the LEDs, music selection, and computational elements (i.e., the role and choices behind lighting patterns, sensor choices, and interaction design). We further documented challenges that arose in students' design progress - both observed independently (i.e., from field note observations) and reported personally (in design notebooks, portfolios, and interviews). Having broken down the project into component parts, we then stepped back to consider the interrelation between the parts and the personal connections and perceived relevance for the students between and across each of these design choices, artifacts, and their overall creative intent.

Further, we looked at aspects of their identity in relation to the communities that they represented in their projects, and traced those themes through their design processes throughout the unit. For instance, each student had core ideas about themselves as individuals and community members (e.g., a gamer, or has family from Mexico). Following up those identified themes in the rest of the data allowed us to understand how those aspects of identity related to other aspects of their final product, and identifying evidence of that throughout the project and instructional unit (e.g., the gamer represented themselves playing favorite video games in their project, and a student with family from Mexico used a photograph from a family trip to an Aztec temple representing their identification with their family and the land). We noted each of these and looked for similarities and differences across the case studies.

The researchers also interpreted the data and results from the analysis to consider the ways in which the unit afforded creative, artistic expression for the participants. Two researchers who were part of the data collection met regularly during analysis to confirm interpretations of the analysis, considering the process of individual case studies and the implications of the design of the unit more broadly. Triangulating the students' work (such as reflections in their design notebooks, interview responses, inprogress and final products, field notes, and artist statements) with our own interpretation of the visual arts education and community-based arts learning fields, we identified ways in which the students participating in this e-textiles unit created meaningful projects that integrated computing competencies, personal reflection of lived experiences, and identity as part of self-identified communities in order to begin developing an artistic voice, with aesthetic, expressive intent in mind.

\section{FINDINGS}

First, we introduce the projects of the focal students and describe the kinds of meaning they conveyed through the process of making their computational art. Next, we identify the three design elements that emerged as key in shaping the artifacts as computational art. Finally we illustrate the multiple ways that students leveraged the medium of e-textiles to create multi-layered, meaningful artifacts through the combination of personal reflection, computation, and physical materials.

\section{The Personalized Dimension of Maker Projects}

One of the first concerns of this unit was that students be able to create personally meaningful artifacts using making and computer science to communicate something about a community that was important to them. Every student did this, with varying interpretations of "community" and what they sought to show (e.g., family, video gaming communities, friendship groups, church, after school clubs, others). Below we describe the four focal students' projects, attending in particular to the kinds of meaning the students constructed through designing and building their e-textile computational artwork. Each project description is accompanied by a picture of the student's project with accompanying annotations about what different elements of the project meant and their artist statements (see Figures 1A-4B). In addition, we explore more deeply one element of media in each student's e-textile mural, from the primary canvas fabric images, to light placement and interaction effects, music choice and coding, and writing. This allows us to examine more closely the ways that students embodied meanings in the visual, physical, interactive, and written aspects of their designs.

Ramon took a literal two-layered approach to his Conceal/Reveal project that represented his participation in the online gaming community Steam (see Figures 1A,B). The Steam logo on the front was printed on canvas, intended to be peeled back (like a book cover) to reveal the second layer where he spent the bulk of his energy coding and drawing. The interior of his project showed, both literally and figuratively, the inside of the video gaming community he wished to reveal. Ramon carefully hand-drew the four gaming characters he chose to display, explaining that, "Well, I guess I'm kinda in all of these characters." (field notes.) This logo alluded to his participation in the Steam gaming community as a multi-faceted player, and as the designer of this e-textile artifact. His choice to have four quadrants meant he was able to show "the amount of games to choose from, how you can play with friends online, and have fun while playing" (post-interview). The two material layers of fabric and design elements represented different aspects of his chosen Steam community. His choice to have the Steam logo on the front layer concealed the interior life of the players he rendered by hand on the inside, revealing multiple personally 


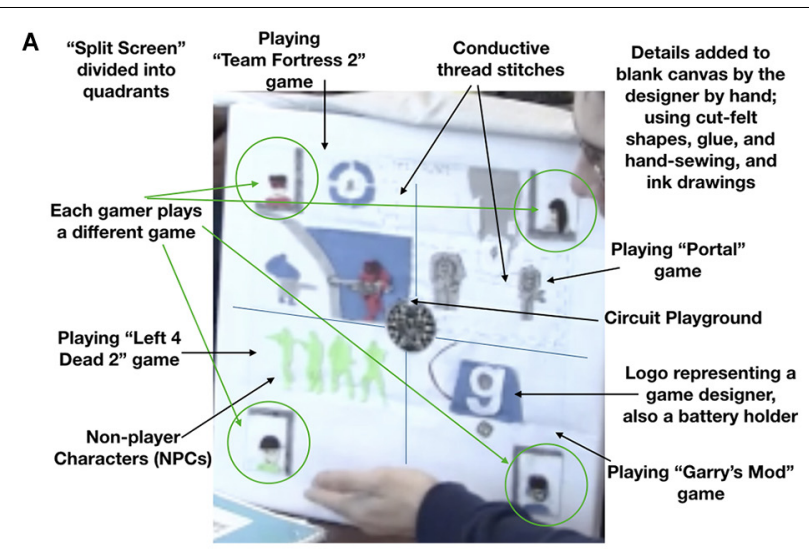

B

\begin{abstract}
Artist Statement
I am a player,

I am also a worker and a writer.

My community is the Steam Community and the world of games.

Together, we can work together, play, and fight online.

We are the players and creators of tomorrow.

This piece here represents my experience with video games by Valve and Steam, the lights show diversity to emphasize the universal appeal in my community.

The sound helps communicate the enthusiasm of my community. Interaction of this project was designed to make people feel welcome and experience joy of my community of games.

Everyday, I choose to reveal the games that are yet to be found by showing the world what lies in Steam.

My choices conceal the surprise from the people which allows me to demonstrate the world what has yet to be found on Steam.

\section{Interaction Instructions}

Shine a light on the Circuit Playground and the LEDs turn on all at once, the "Team Fortress 2 " theme song plays
\end{abstract}

FIGURE 1 | Ramon's Conceal/Reveal Project, Artist Statement, and Interaction Instructions.

relevant elements of his life: the anonymity gained from gaming online and the personal nature of building community on Steam (field notes). Thus Ramon deftly used the two material layers of fabric to convey layered meaning about his video gaming community and his different identities of participation within it. The other elements of the project accentuated this theme. When a light shone on the Circuit Playground, the Team Fortress 2 theme song played (one of the games represented), and the LEDs flashed, accentuating the various characters on the inside fabric. Ramon's project aimed to show the enthusiasm, diversity, joy of play, and appeal of the online gaming communities he participated in (see artist statement in Figure 1B), and how they were meaningful to his life.

Jae, a 10th grade Vietnamese student, came to the project with skepticism about his interest and abilities in computing, but found music to be an entryway into coding. Of all the students featured in this paper, Jae initially felt the least confident with computing, saying "I'm not that good in logical stuff. And I'm also kind of lazy. That's why I don't really like the coding," (post-interview). Still, he started building his project around a photograph that he took while traveling with his family in Korea, which showed a neighborhood corner with colorful foliage in red, orange, and yellow (see Figure 2A). The battery for the
Circuit Playground was concealed by a piece of felt that was designed to blend into the sky as a white puffy cloud. The song Jae selected and coded was "As If It's Your Last" by the Korean-pop group BLACKPINK. The song was particularly difficult to code since it involved multiple arrays, but Jae found the motivation to persevere in his desire to play the music, which sounded different coming from a small piezo buzzer but "it still reminds me of my memories but there's something new in it so I really like it" (post-interview). When a light shone on the Circuit Playground, the red and yellow LEDs placed amongst the leaves of the trees on the street corner glowed, and the song played. This project demonstrated his love of music and dance, represented a meaningful trip he took with family to Korea, and provided a pathway to coding that tapped into his sense of creativity and love of music (see Figures 2A,B).

An 11th grade Latinx female student at the time, Zoila rendered her imaginative design by hand, using colored pencils to represent personally meaningful video game characters playing music in an imagined space featuring an ocean and cliff. These represented her participation in jazz band (music), visual art, and video games (see Figure 3A). Zoila intentionally placed LEDs on top of the musical notes on her canvas "to represent the life and happiness music brought to me" (final portfolio). Synchronizing the lights with her music, the Kirby video game theme song, she coded a "weird pattern where some [lights] blink and others fade,

$\begin{aligned} & \text { Circuit } \\ & \text { Playground } \\ & \text { Conductive } \\ & \text { thread stitches }\end{aligned}$
$\begin{aligned} & \text { Red LED } \\ & \text { Yellow LED }\end{aligned}$
"I have used
blinking yellow,
red lights to
show the
supportive of
my Korean's
culture
community...
and scenery."




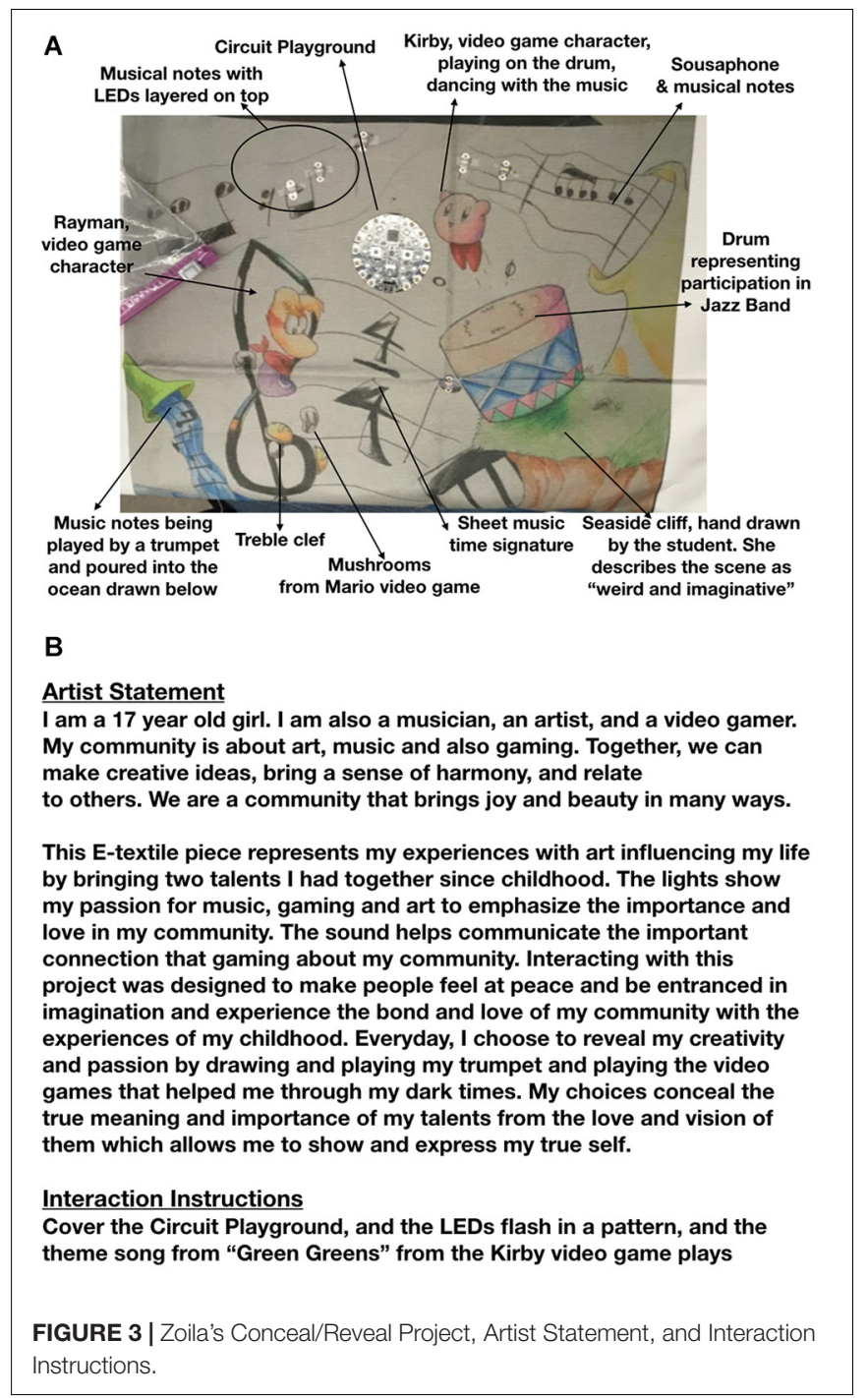

representing how a song can be sweet and silent or bombastic" (Ibid.). Zoila wanted to elicit certain feelings in the people who interacted with her project: "I want people to feel happy, awed, and at peace. When their hand gets near enough, the lights will turn on and start blinking. While they blink, they will play the song I coded." (Ibid.). The interaction, lighting and music combined to engage viewers in the harmony, joy and creativity that she felt in the coming together of the different perspectives of the art, music, and video game communities important to her.

Finally, describing Paloma's project would be incomplete without attending to her writing. A 10th grade female Latinx student, Paloma used her project to explore and communicate her identity within art and computing worlds. She focused her project on a digital self-portrait using brush-strokes in an impressionist style, which showed a realistic rendering of herself with eyes closed (see Figure 4A). She placed the Circuit Playground at the crown of her head, with LEDs scattered in her hair. When a light shone on the light sensor, the LEDs glowed, and the song Mr. Bluesky played. She explored the meanings of all of these elements in her writings and reflections throughout the project. In an

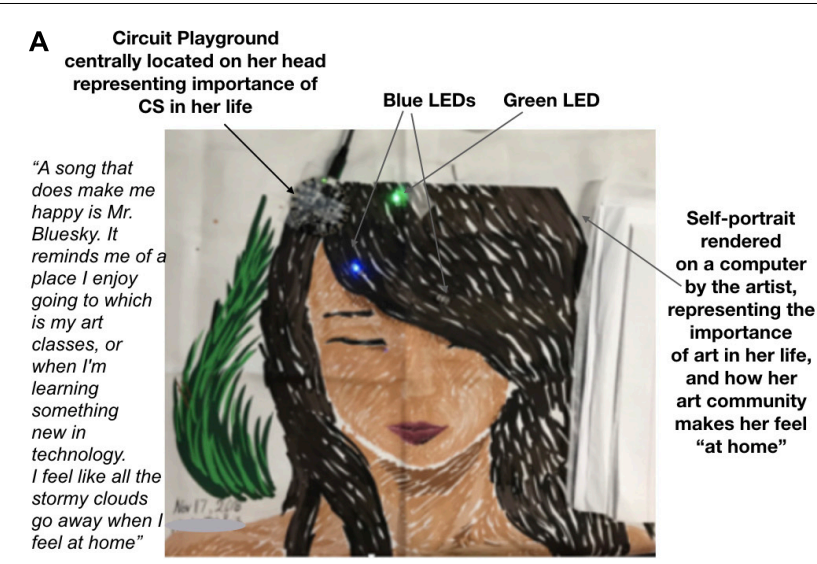

\section{B}

Artist Statement

This piece represents my experience with computer-science based technologies combined with art by learning how to code in the computer language Arduino and sewing lights that carry electricity.

The lights show hope and a message to emphasize opportunities in my community.

The sound helps communicate excitement of what you can find about my community.

Interacting with this project was designed to make people see what I am capable of making and to see all the possible creations you can make. So that people can experience a preview of my community.

Everyday, I choose to reveal the process of what goes in when creating an interactive design by learning how to code a project people can interact with.

My choices conceal my troubles from artwork allows me to feel happy.

\section{Interaction Instructions}

When a flashlight shines on the light sensor of the circuit playground, the LEDs begin to fade in and out, Mr. BlueSky song plays.

FIGURE 4 | Paloma's Conceal/Reveal Project, Artist Statement, and Interaction Instructions.

"I am" poem written early in the construction phase, she wrote, "I am a budding coder is doing her best to grasp the concepts of computer science, so that I can have marvelous creations be produced by technology" (design notebook). This excerpt showed Paloma grappling with her identity as a budding coder and positioning technology as something that created things for her, rather than situating herself as an agentic contributor to the code of her project. However, throughout the project her conceptualization of herself as both an artist and computer scientist deepened in meaningful ways. Evidence for this is in her final artist statement (see Figure 4B) where she wrote about the experience of designing and building her project alongside her intended expression with the artwork: "This piece represents my experience with computer-science based technologies combined with art by learning how to code in the computer language Arduino and sewing lights that carry electricity." In this line of her artist statement, Paloma expressed a more nuanced understanding of the technology she had been working with for several months, and positioned herself as an active learner and contributor to the technology and CS content included in her final project. Through her construction and coding along with her writing, Paloma leveraged this project to position herself more squarely in both the art and computing worlds. 
These four students' designs and design processes exemplify the ways that all participants in the class made unique, creative, original work that connected one or more communities they participated in outside of class (e.g., family, video gaming communities, skate parks, church, after school clubs, others) to their lived experience in the CS classroom coding and making these artifacts. Each student explored personal connections to their communities through the media of digital images on fabric, careful placement of LEDs and electronic components, coded lighting and interaction effects, programmed music, and accompanying written reflections and statements. In the following sections, we will review the art and computational dimensions of these maker activities that allowed the students to convey their intended meanings.

\section{The Arts Dimension in Maker Projects}

In analyzing students' artifacts and design processes, we identified three distinct artistic elements that were important in supporting students' creative, meaningful CS designs and distinguish this project from many other STEM maker projects: (1) intent behind the work; (2) conscious, on-going reflections on their design throughout the process; and (3) designing for an audience. Together these three elements helped students create computational art that reflected an individual's experience in a larger world and positioned their actions as personally relevant and contributing to a larger community-moving from personal to community relevance for the maker-artists. They also reflect important qualities of arts education, characteristics that help the Conceal/Reveal project to meet certain arts education criteria, including the ability to synthesize and relate knowledge and personal experiences to make art, and relating their artistic ideas and projects with personal meaning and external contexts (National Coalition for Core Arts Standards, 2014). Attending to these art education standards supported students to make personally meaningful, interactive, computational art. Below we share ways that these three elements helped make these community murals pieces of expressive computational art rather than just CS maker artifacts, using Zoila's creation as a space to explore how each of these qualities supported her design process.

In their mural artifacts, students brainstormed and refined their ideas to ultimately demonstrate unique, personally meaningful intent behind their community murals. Here, we identify visual art as a carefully crafted artifact which has expressive intent (Gnezda, 2009), in that it is built with the intent of communicating something of personal relevance to a potential viewer. As an example, Zoila represented her love of three distinct communities (jazz band, video gaming, and her art practice) by rendering a unique, imagined world where she could express her creativity through CS practices. She expressed her intent behind her piece in her writing. In her design notebook, she said "I want my final project to demonstrate my artistic skills and my passion for music and video games.... chose this because these communities help define who I am and what I love" (design notebook). This example of reflective writing shows Zoila's intent to design a creative project that expressed elements of herself and her creative intent in layered, meaningful ways including the visual representation she drew, the LEDs and their blinking pattern, and the music she coded. Ultimately we see this as an example of the creative intent behind her project-it is beyond a pretty picture that blinks and sings, it is a piece of expressive computational art that was designed and crafted with personal intent. This intentional reflection, visible only through reading her written reflective prompts, exposes some of the thinking and personal meaning behind the design of students' projects. This further connects this maker project to the field of arts education, by revealing some elements of the personal meaning behind this project. It also aligns this work to the body of research in arts education more broadly linking education to issues of social justice (Desai and Chalmers, 2007).

Students also engaged in conscious reflection in writing throughout the design process-in design notebooks, artist statements, and warm-up reflections-to check-in with themselves to make sure their final product was reflecting their intent. In this project, we see evidence of students engaging in a meaningful and reflective creative process (e.g., Fiske, 1999; Eisner, 2002), which produced a meaningful final project. The written reflections and iterative making process supported that reflective experience. For instance, in reflecting on her song choice, Zoila wrote, "This song reminds me of my video game community because it not only comes from a game, but represents the part that has been with my [sic] almost for life. It brings the joy and happiness that I don't tend to have because it reminds me of my greatest memories. It also were $[s i c]$ the first game I ever played." (Zoila's design notebook) Here Zoila describes the reflective import of her song choice. She used a familiar video game theme song that others would likely recognize when played, but her reflections revealed a more nuanced personal relevance for her selection of this song, connecting elements of her past and her present.

Further, the process of learning to code a song became the "best part of making the project," and helped her to integrate both her artistic and computational aspirations. Throughout the design process, Zoila said that the writing prompts and reflections "strengthened what this [project] means to me. This is who I am, this is what makes me and I shouldn't deny who I am. I should be allowed to show how creative I am, to not be afraid or nervous of it, just go for it" (post-interview). Zoila, a confident artist and quiet student, here identifies the important role that writing played in supporting her understanding of her artistic process, and her identity. While making this project, she strengthened her affiliation with her art community by creating representational artwork she was proud of (design notebook) and that was recognizable to her peers, which supported feelings of affiliation between herself and the classroom community. Her success with the computational elements also seems to have emboldened her to express who she is, and share her interests with others. Thus, the reflections on her expressive computational artwork distinguished this project from a more traditional Maker project which often lack that level of reflection. Each piece or layer was not just functional, it had embedded meanings. Layering emotional, personally evocative memories into this artifact through computing components including music and code, Zoila made connections across time and between communities she identified with, and deepened her identification with computing. 
In these ways, Zoila's and other students' reflections shaped not only their designs but also their senses of self and future aspirations with the communities they identified in their artifacts as well as the arts and computer science disciplines associated with the project.

Finally, students designed for an audience, conceptualizing the life of an artifact beyond the "making" process and into the exhibition process where the piece could stand alone and be meaningful to both the designer/maker and other viewers (e.g., Greene, 1995; Magnifico, 2010). In particular, when tasked with designing an interaction with a viewer in mind, students considered their artifact design from multiple perspectives: their own, as the insider/designer/maker, and the viewer, as an outsider. Zoila did this in her project as she designed the interaction with the light sensor to trigger the lights and music. She created a background image that was enticing in its familiarity and its creativity, using familiar video game characters and musical instruments in fantastical environments to encourage viewers to investigate further. She then considered how she wanted people to feel when interacting with her project, when responding to a reflective prompt in her design notebook. She wrote, "I want people to feel happy, awed, and at peace. I want people to interact with it by someone approaching the project. I want it to light up and blink with the song when someone comes near" (design notebook). From this initial iteration, Zoila altered her plan in order to make it feasible in the allotted time, and used a light sensor being covered by a hand, to trigger the lights and music. We see her iteration later in her planning as she wrote: "I want people to cover the circuit playground with their hand. When their hand gets near enough, the lights will turn on and start blinking. While they blink, they will play the song I coded into the circuit playground" (design notebook). Her design considered how to entice viewers to interact with her project, represented personally meaningful elements of her life, and allowed space for the viewers to have their own experiences in and make their own connections with the familiar characters. Dedicating concerted time and effort in the design and building process to consider audience experience, or what they as the designer wanted the viewer to consider and feel when looking at or interacting with their artifact, contributed to unique, personalized choices from the students in designing interaction and their projects at large.

Intent, conscious reflection, and design for an audience are all concepts important to arts education that supported students' expressive work in their Conceal/Reveal maker mural projects. While meeting core areas of arts education, these three qualities also enabled students to make deeper connections to their personal lives in ways available and visible to outside viewers. We see these as the three primary qualities of this project that allowed students to make connections to their personal lives and to their lived communities in a way that is distinct from many maker activities that prioritize individual making over community designs and impact. Throughout the design process, students reflected on their own feelings and the feelings they hoped to generate in others, imbuing these designs with intentional, communicative meaning in ways that often go neglected in maker pieces designed less for expression, and more for functionality. Freedom of expression, within supported guidelines of the parameters of the project, allowed students to be and feel creative, express personal elements of their lived experiences, and imagine a future world for themselves while considering how their lives, actions, and relationships in communities impact the larger world.

\section{The Computational Dimension in Maker Projects}

The various modes of e-textiles, namely the visual, material, and virtual elements of the projects, combined expressive aesthetics with challenging computational concepts. Here we consider the skills and knowledge students developed in order to accomplish their expressive CS art. Perhaps most obvious on the displays is the presence of lights and associated lighting effects, achieved by designing computational circuitry, sewing it with conductive thread, troubleshooting the construction, and coding (and debugging) lighting sequences. Students engaged in this technical work in order for the chosen lights to magnify meanings on their canvases. In interviews and surveys across the class, students suggested that they intentionally designed LED colors, placements, and patterns to amplify meaning in their projects.

As an example, Zoila used light placement and lighting effects to connect further to her identified communities of visual arts and music. She placed LEDs on top of the musical notes and amongst the video game characters she had drawn on the background canvas to emphasize the musical, artistic, and gaming communities, describing that "the lights represent my bright passion for music" (design notebook). One of the things she was most proud of about her project was that "I managed to sew on my lights. Not only did I do that, but I managed to code them to turn on. I'm glad that the stitching didn't get in the way of my drawing or make it lose meaning" (design notebook). Here Zoila emphasized the effort it took to learn how to sew circuits and code them, alongside her desire for the lights and sewn circuitry to complement her design rather than distract from it. She also mentioned that the coding was a particular challenge: "I had issues on coding the right pattern too. I [sic] program had several crashes and I needed to change some parts until finally I got what I wanted" (final portfolio). This demonstrates the intimate connection of computational skills to the artistic intent of the design, working through multiple versions to achieve the desired visual effect. Indeed, the very effort to make sure the lights and pattern were just right, involved significant work debugging code, a key computational concept.

Music as an evocative artform was another powerful element in students' community murals. Song selection and the coding process were both meaningful aspects of the process and final pieces. Students leveraged music as a tool to build complex, multi-sensory experiences for the viewer of the expressive computational artwork. In addition to selecting personally relevant songs, the coding process added an additional layer of meaning to the song and final e-textiles. Coding a song involved a challenging process of transposing a written song into code, giving each note (and rest) a number for tone (in hertz) and duration/rhythm (in milliseconds). Students coordinated tones 
and durations through two arrays, sometimes even coordinating lights with different parts of the music. Personal connections to the songs encouraged students to persevere in the face of challenging coding concepts and bugs.

For instance, Jae selected a favorite song by a Korean-Pop (K-pop) band, which augmented his background image of a neighborhood in Korea and the connection he felt to K-pop dancing and performance. He reflected on the significance that coding a favorite song added to his project, sharing, "It's interesting to hear it [the song] in a different way and it's also interesting to coding it myself" (Post-interview). The process of coding a favorite, personally relevant song was significant for Jae, especially since this was his first experience coding in Arduino, and it was a challenging task. He not only learned programming, but built a more personal connection to the song, his past, his interests, and the CS community as a coder. Through the process of transposing the song from the full K-pop band to a Circuit Playground that plays one note at a time (as opposed to a chord, where multiple notes are played at one time), the sound of the song was transformed by nature of the technology and sheet music that was used to code the song for his project (see Figure 5). After coding the song, Jae was able to listen to the song and hear it in a new way, as a new version of the song that he had an active role in creating. Jae noted this, sharing "I get to create it [a favorite song] in a different way and try to listen to it, it still reminds me of my memories but there's something new in it so I really like it" (post-interview). Listening to the final version provided another opportunity for personal meaning making and reflection for Jae. This process enabled Jae to connect his experiences in a CS class learning to code with his previous experiences in Korea, and with his K-pop community in the US. The incorporation of music in the mural added depth and complexity in both computation and in personal connections to students' lived experiences and connections to community.

Interaction with an e-textile mural for this project meant students were asked to code utilizing one of the onboard sensors of the Circuit Playground: light, sound, or temperature. Most students used the light sensor so that when a flashlight was shone directly on the Circuit Playground the LEDs turned on or a song played. This was likely due to the fact that when teaching interaction, the researchers shared a sample project and code using a light sensor. This required learning to read and test numerical inputs from the sensor, decide what threshold(s) should trigger an action, code that with conditional statements and operators (i.e., sensorvalue $>500$ ), and repeatedly test and tweak the interaction until it worked consistently with different people. Incorporating a coded interaction for this project encouraged students to consider the impact their art would have on an observer-providing an opportunity for reflexive consideration of what an outsider would see when they encountered their project, and what kind of interaction would be useful to support or elicit the intended feeling the students wanted the interaction to foster in the viewer. During class, we discussed the importance of art and design influencing the audience or those interacting with and viewing the designed artifact and artwork. Students considered this when designing and coding the interactions of their projects.
Zoila used the light sensor in a unique way, requiring the viewer to cover the Circuit Playground (to reduce light instead of magnify light) in order for the song to play and light patterning to be triggered. Her intention was for each viewer to step forward and place their physical hand on her project to reveal the inner life of Zoila, how she saw herself and the world, as expressed through lights, visuals, and music. To accomplish this effect, after much testing, she coded the light sensor to trigger when the threshold was below 62 (on a scale of $0-1023$ ). This worked best with the ambient light in the classroom but did not require the user to completely cover the Circuit Playground. By providing the necessary close-looking and introspective gesture of covering the Circuit Playground, Zoila used certain programming and abstractions to create a meaningful, personal moment for the viewer of the piece, and for herself, the artist.

Thus Zoila coded the interaction of her project to encourage folks to step into her community, to better understand her experiences and who she was. During the design and making phases, based on the ways that she iterated on her interaction design-moving from abstract (a person walks by the piece) to concrete (a person covers the circuit playground with their hand) - we understand her actions to mean that she visualized viewers seeing her project, being drawn into the work, stepping forward to take a closer look, and place their physical hand over the Circuit Playground sewn onto her project. Coding for interaction was another opportunity to deeply consider the role that a viewer would play in completing the project. Through this project, coding and designing the interaction provided a platform for Zoila to invite her peers and other community members into her hidden world of imagination rendered in her project.

Finally, throughout the design, code, and creation process, students wrote regularly. Often this was directed with prompts for reflection in their design notebooks, where students reflected on communities that were important to them, completed "I am" poems about their identities, and considered challenges they had faced in constructing their projects. At two timepoints they also completed process-based portfolios (Lui et al., 2018; Jayathirtha and Kafai, 2019) where they communicated about changes they had made in their projects, whether because of design decisions or because of problems that had come up. Finally, in their artist statements and instructions students brought together their final communication about their projects, explaining what each part of their project was about, how to interact with it, and what it meant to them. Across these collected writings, we saw evidence of computational communication as students grappled with tensions in their lives, including the world they lived in, and the world they would like to see in the future. Providing a space to write and reflect on how their actions in a CS and Art class might transform their lives in the future was a useful, grounding tool for the students to begin articulating their goals in a way that was not typical in this course before the e-textiles unit.

Zoila, a self-identified "talented person with many skills and knowledge" (design notebook) used this project as an opportunity to demonstrate her skill as a computational artist. Her drawing technique allowed her to render representational cartoons that her classmates could recognize, and her ability to code lights in a flashing pattern and code music from the video game Kirby 


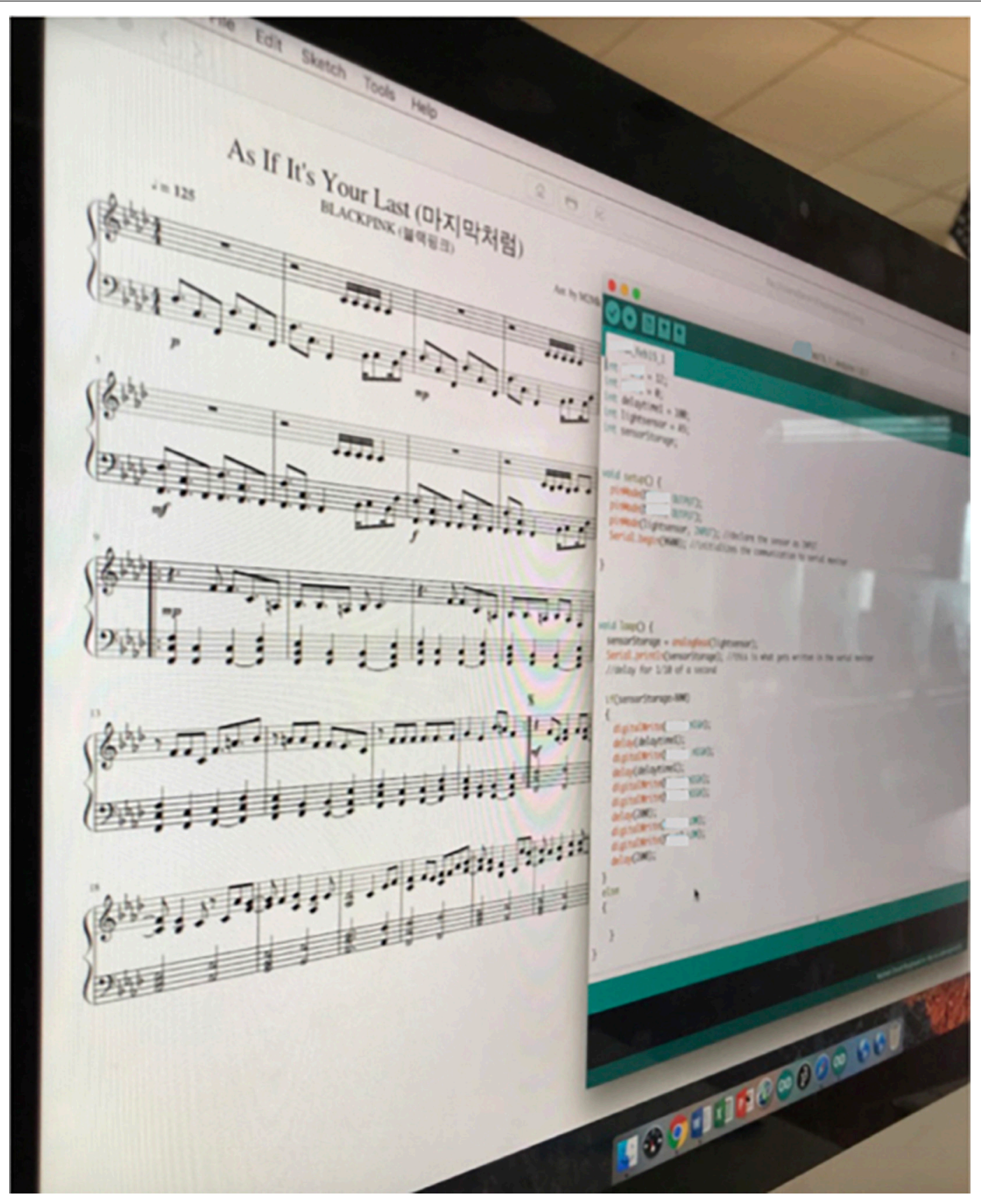

FIGURE 5 | Jae's computer screen as he transcribed musical notes into code.

emphasized her competence in both traditional art practices and computational contexts. These elements were visible by viewing her artifact, and interacting with it. However, we see the deeply personal connections she made between the three communities represented in her project through her reflective writing. Her writing in her design notebook shows a longterm connection to the creative arts, and how passionate she is about these facets of her life. "I have been a musician since 6th grade and have played multiple instruments throughout the years. I am also an artist and I enjoy drawing both on paper and computer. This passion of mine has been with me for a long time (design notebook)." When describing what she liked about her art community in her design notebook in the early design process, she wrote "tranquility, helps me connect more with the world, ability to use this to show who I am, take away the stress."

Through her writing, we see Zoila reflecting on the role that the practice of art plays in her life: promoting tranquility and reducing stress in her life, and strengthening her ability to be confident in herself and represent herself for who she is. In her 
writing here she also positions art as one way she can build community between herself and others by connecting over shared interests (i.e., video games), or through interacting with her artwork (she as the artist, the others as an admiring viewer). By looking at her project, one can see a well designed and crafted computational artifact. However, through her reflective writing, we can see the layers of personal meaning, histories, and her hopes for the future, and how they were integral in the design and building of the final artifact. Writing provided a reflective opportunity to plan and express her intent and inspiration behind the project, and a place to synthesize the process of learning to code lights and music, with expressing something personal about her lived experiences. This connection not only to the self or the individual learning computing content, but of the student to their own communities through the process of coding, is important to consider.

\section{DISCUSSION}

In this paper we leveraged arts-based making in a computer science education classroom in order to support students' meaning-making, artistic expression, and computational learning. In the introduction we outlined challenges with the current predominance of STEM-focused work in maker education, including a tendency to emphasize scientific or technical function over social or political purpose, expression, creativity, or critical engagement (e.g., Vossoughi et al., 2016). While previous efforts have been made to support students in making personally meaningful projects through maker education (e.g., Litts et al., 2019; Peppler and Keune, 2019) these have tended toward thoughtful crafts more than expressive artwork. Instead, in this study, we emphasized arts-based STEAM practices such as conscious intent, consideration of audience, and conscious reflection through artistic communication. Our analysis of four case studies demonstrates how these emphases supported students' computational art in ways that engaged them in critical thinking about communities they participate in as well as computational and arts-based concepts and practices that support disciplinary learning in school. Below we consider what this means for student engagement, computational learning, and maker education in formal contexts.

In shifting from a crafts-based maker approach to an artsbased maker studio model, we emphasized three areas of artbased practices, all of which influenced students' computational art designs as well as their engagement in arts and computer science communities. First, developing personally meaningful intent behind their computational artifacts supported students' abilities to claim participation in communities both in and out of school, and provided a set of tools to represent and refine their ideas to their peers and to themselves. Second, designing their work with an audience in mind acted as a bridge from the individual maker to the collective communities of which they were members. Finally, the reflection and feedback in this project-by the makers and their peersprovided an opportunity for students to identify and share elements of their lives they valued. Students tied their artifacts to the future and the past, to arts and computing communities, between personal and school lives. These kinds of connections suggest further research into the role that making expressive computational art might play in supporting and connecting identity development and belonging across different communities.

This research contributes actionable elements of pedagogical design for practitioners or researchers to implement in artsinformed maker spaces moving forward. Incorporating artsbased practices such as design directives, aesthetic audience considerations, and reflective artist statements into a maker curriculum would allow makers to engage with artifact production in richer ways by using a wider variety of materials and forms of representations and reflections (Hetland et al., 2013). Maker education promotes iteration, creative uses of materials, and a do-it-yourself mindset (Honey and Kanter, 2013; Peppler and Bender, 2013; Halverson and Sheridan, 2014; Sheridan et al., 2014). This approach, adding personal reflection, and aesthetic considerations to a maker project can lead to meaningful engagement with both STEM and art learning, and may promote reflexivity in young people participating in the project. Given the democratic aims in maker spaces, aiming to broaden participation in STEM and promote interest-driven learning, providing the skills and habits of mind to attend to both content learning and personal or community-based concerns adds an additional layer of meaning to the resultant maker artifacts and making experience.

Through the entire project students arguably learned more sophisticated computing concepts than in other e-textiles projects for K-12 students (e.g., "for loops," arrays), yet at the same time these were authentic to the design context. Integrating music and interactive effects required using arrays, variables, conditionals, and sensing in ways not previously used outside of university contexts with e-textiles (Jayathirtha and Kafai, 2019). Motivated by a favorite song or the desire to create an emotional reaction in a viewer helped students persevere through challenging computing tasks. In other words, the artistic focus of this project did not detract but rather magnified the CS learning opportunities for students. This suggests many possibilities for meaningful STEAM pedagogy where arts and various STEM-related disciplines can work together to support students' engagement and learning. There are many more possibilities to create meaningful design directives with e-textiles. Incorporating accelerometer sensing to inspire choreographic practices in dance or performance art as well as learning in math and physics, or considering color effects, temperature sensing, or different types of electrical sensors that work through stretch or pressure. Further, while we have explored arts and CS through e-textiles, future studies could consider other maker tools as means of creating expressive computational art.

One further motivation for this study was to support the expansion of maker education from informal learning settings into a formal learning setting through the incorporation of arts-based learning into making with e-textiles in a computer science class. Our analysis suggests that the project was successful in engaging students in learning appropriate to an arts and computer science course in secondary education. In particular, 
the design directive that matched certain computational effects (i.e., interaction) with arts perspectives (i.e., reflective prompts on how to make an audience feel) seems particularly apropos to this kind of educational design. However, many more possibilities can be explored in formal education in different subject areas and with different grades. In particular, the three arts-based practices we focused on this project (e.g., intent, audience, and reflection) are only a few of many options for drawing on expressive art in designing maker artifacts. We look forward to more work that explores richer expansion of a maker studio model through different pedagogical designs and contexts.

Too often, maker projects in STEM learning are predicated on learning to use a specific tool to gain a particular skill, and the skill is evidenced by the craft that is produced, as seen with the early popularity of maker spaces, sharing designs and tutorials for learning skills to make artifacts (Martin, 2015). This project productively taught students to competently use media and technology, while requiring personal reflection and expression-a relatively novel approach to maker education. This holds possibilities for future research and pedagogy which positions STEAM leaning as transformative for learners in both the arts and STEM content learning (Peppler and Wohlwend, 2018). More research and pedagogical design is needed to understand the complexities of integrating elements of an art studio into STEM-based classrooms in meaningful ways.

\section{DATA AVAILABILITY STATEMENT}

Due to the private nature and identifiable information of the data sets generated for this study, the data sets are not available to others.

\section{REFERENCES}

Anderson, C. (2012). Makers: The New Industrial Revolution. New York: Crown. Banzi, M. (2011). Getting Started with Arduino, 2nd Edn. Sebastopol: Maker Media, Inc.

Barton, A. C., and Tan, E. (2019). Designing for rightful presence in STEM: the role of making present practices. J. Learn. Sci. 28, 616-658.

Barton, A. C., Tan, E., and Greenberg, D. (2016). The makerspace movement: sites of possibilities for equitable opportunities to engage underrepresented youth in STEM. Teach. Coll. Rec. 119, 11-44.

Blikstein, P. (2013). "Digital fabrication and "making" in education: the democratization of invention," in FabLabs: Of Machines, Makers, and Inventors, eds J. Walter-Herrmann, and C. Bc̈hing (Bielefeld: Transcript-Verlag), 1-21.

Blikstein, P., and Worsley, M. (2016). "Children are not hackers: building a culture of powerful ideas, deep learning, and equity in the maker movement," in Makeology: Makerspaces as Learning Environments, eds K. Peppler, E. Halverson, and Y. Kafai (New York: Routledge), 64-80.

Buechley, L. (2006). "A construction kit for electronic textiles," in Proceedings of the 10th IEEE International Symposium on Wearable Computers (Piscataway, NJ: IEEE), 83-90.

Buechley, L., Jacobs, J., and Mako Hill, B. (2013a). LilyPad in the wild: technology DIY, e-textiles, and gender. Text. Messag. 147:157.

Buechley, L., Peppler, K., Eisenberg, M., and Yasmin, K. (2013b). Textile Messages: Dispatches from the World of E-Textiles and Education. New Literacies and Digital Epistemologies. New York, NY: Peter Lang Publishing Group, 62.

\section{ETHICS STATEMENT}

The studies involving human participants were reviewed and approved by the University of Pennsylvania Institutional Review Board. Written informed consent to participate in this study was provided by the participants' legal guardian/next of kin.

\section{AUTHOR CONTRIBUTIONS}

LL and DF facilitated the curriculum for the full duration of the unit. LL, DF, and YK contributed conception and design of the study. LL performed the coding and analysis. DF and YK performed the secondary analysis and review. All authors wrote sections of the manuscript, contributed to manuscript revision, read and approved the submitted version.

\section{FUNDING}

This research was funded through Google's Computer Science Education Research Award. Any opinions, findings, and conclusions or recommendations expressed in this paper are those of the authors and do not necessarily reflect the views of Google.

\section{ACKNOWLEDGMENTS}

We are grateful to the students and learning community at the school for providing the space to pilot this intervention. Additional support from researchers at the University of Pennsylvania was crucial in the development of this program and manuscript.

Cohen, J., Jones, W. M., Smith, S., and Calandra, B. (2017). Makification: towards a framework for leveraging the maker movement in formal education. J. Educ. Mult. Hypermedia 26, 217-229.

Colucci-Gray, L., Burnard, P., Cooke, C., Davies, R., Gray, D., and Trowsdale, J. (2017). Reviewing the Potential and Challenges of Developing STEAM Education Through Creative Pedagogies for 21st Learning: How Can School Curricula be Broadened Towards a More Responsive, Dynamic, and Inclusive form of Education?. London: British Educational Research Association.

Desai, D., and Chalmers, G. (2007). Notes for a dialogue on art education in critical times. Art Educ. 60, 6-12.

Dissanayake, E. (2003). The core of art-Making special. J. Can. Assoc. Curriculum Stud. 1, 13-38.

Dougherty, D. (2012). The maker movement. Innovations 7, 11-14.

Efland, A. (1990). A History of Art Education: Intellectual and Social Currents in Teaching the Visual Arts. New York, NY: Teachers College Press.

Eisner, E. (2002). The Arts and the Creation of Mind. New Haven, CT: Yale University Press.

Ellen, W., and Stéphan, V. L. (2013). Educational Research and Innovation Art for Art's Sake? The Impact of Arts Education: The Impact of Arts Education. Paris: OECD publishing.

Fields, D. A., Kafai, Y., Nakajima, T., Goode, J., and Margolis, J. (2018). Putting making into high school computer science classrooms: promoting equity in teaching and learning with electronic textiles in exploring computer science. Equity Excell. Educ. 51, 21-35. doi: 10.1080/10665684.2018.143 6998 
Fiske, E. B. (ed.) (1999). Champions of Change: The Impact of the Arts on Learning. Denver, CO: Arts Education Partnership.

Gadsen, V. (2008). The arts and education: knowledge generation, pedagogy and the discourse of learning. Rev. Res. Educ. 32, 29-61.

Gnezda, N. M. (2009). The potential for meaning in student art. Art Educ. 62, 48-52.

Goode, J., Chapman, G., and Margolis, J. (2012). Beyond curriculum: the exploring computer science program. ACM Inroads 3, 47-53.

Greene, M. (1995). Releasing the Imagination: Essays on Education, The Arts, and Social Change. San Francisco, CA: Jossey-Bass Publishers.

Gude, O. (2013). New school art styles: the project of art education. Art Educ. 66, 6-15.

Halverson, E. R. (2013). Digital art making as a representational process. J. Learn. Sci. 22, 121-162.

Halverson, E. R., and Sheridan, K. M. (2014). "Arts Education and the Learning Sciences," in Cambridge Handbook of the Learning Sciences, 2nd Edn, ed. R. K. Sawyer (New York, NY: Cambridge University Press), 626-646.

Harris, A., and de Bruin, L. R. (2018). Secondary school creativity, teacher practice and STEAM education: an international study. J. Educ. Change 19, 153-179. doi: 10.1007/s10833-017-9311-2

Hatch, M. (2014). The Maker Movement Manifesto. New York, NY: McGraw-Hill.

Hetland, L., Winner, E., Veenema, S., and Sheridan, K. M. (2013). Studio Thinking 2: The Real Benefits of Visual Arts Education, 2nd Edn. New York, NY: Teachers College Press.

Honey, M., and Kanter, D. E. (eds) (2013). Design, Make, Play: Growing the Next Generation of STEM Innovators. Abingdon: Routledge.

Hsu, Y. C., Baldwin, S., and Ching, Y. H. (2017). Learning through making and maker education. TechTrends 61, 589-594.

Jayathirtha, G., and Kafai, Y. B. (2019). "Electronic textiles in computer science education: a synthesis of efforts to broaden participation, increase interest, and deepen learning," in Proceedings of the 50th ACM Technical Symposium on Computer Science Education (New York, NY: ACM), 713-719.

Kafai, Y. B., Fields, D. A., Lui, D. A., Walker, J. T., Shaw, M. S., Jayathirtha, G., et al. (2019). "Stitching the loop with electronic textiles: promoting equity in high school students' competencies and perceptions of computer science," in Proceedings of the 50th ACM Technical Symposium on Computer Science Education, 1176-1182.

Kafai, Y., Fields, D., and Searle, K. (2014). Electronic textiles as disruptive designs: supporting and challenging maker activities in schools. Harv. Educ. Rev. 84, 532-556. doi: 10.17763/haer.84.4.46m7372370214783

Katehi, L., Pearson, G., and Feder, M. (eds) (2009). Engineering in K-12 Education: Understanding the Status and Improving the Prospects. Washington, DC: The National Academies Press.

Lai, A. (2012). Culturally responsive art education in a global era. Art Educ. 65, $18-23$.

Litts, B. K., Kafai, Y. B., Lui, D. A., Walker, J. T., and Widman, S. A. (2017). Stitching codeable circuits: high school students' learning about circuitry and coding with electronic textiles. J. Sci. Educ. Technol. 26, 494-507.

Litts, B. K., Widman, S. A., Lui, D. A., Walker, J. T., and Kafai, Y. B. (2019). A maker studio model for high school classrooms: the nature and role of critique in an electronic textiles design project. Teach. Coll. Rec. 121:n9.

Lui, D., Jayathirtha, G., Fields, D., Shaw, M., and Kafai, Y. (2018). "Design considerations for capturing computational thinking practices in high school students' electronic textile portfolios," in Proceedings of the International Conference of the Learning Sciences, Vol. 2018, 721-728.

Lui, D., Litts, B. K., Widman, S., Walker, J. T., and Kafai, Y. B. (2016). “Collaborative maker activities in the classroom: case studies of high school student pairs' interactions in designing electronic textiles," in Proceedings of the 6th Annual Conference on Creativity and Fabrication in Education (New York, NY: ACM), 74-77.

Maeda, J. (2013). STEM + Art = STEAM. STEAM J. 1:34. doi: 10.5642/steam. 201301.34

Magnifico, A. M. (2010). Writing for whom? Cognition, motivation, and a writer's audience. Educ. Psychol. 45, 167-184.

Martin, L. (2015). The promise of the maker movement for education. J. Pre Coll. Eng. Educ. Res. 5:4.
National Coalition for Core Arts Standards, (2014). Rights Administered by the State Education Agency Directors of Arts Education. Dover, DE: National Coalition for Core Arts Standards.

National Research Council, (1999). Being Fluent with Information Technology. Washington, DC: The National Academies Press.

Olsen, E., Tofel-Grehl, C., and Ball, D. (2018). The temperature-sensing lunchbox. Sci. Scope 42, 47-52.

Pearse, H. (1983). Brother, can you spare a paradigm? The theory beneath the practice. Stud. Art Educ. 24, 158-163.

Peppler, K., and Bender, S. (2013). Maker movement spreads innovation one project at a time. Phi Delta Kappan 95, 22-27.

Peppler, K., Halverson, E., and Kafai, Y. B. (2016a). Makeology: Makers as Learners. London: Routledge.

Peppler, K., Halverson, E., and Kafai, Y. B. (2016b). Makeology: Makerspaces as Learning Environments. London: Routledge.

Peppler, K., and Keune, A. (2019). "It helps create and enhance a community": youth motivations for making portfolios. Mind Culture Act. 26, 234-248.

Peppler, K., and Wohlwend, K. (2018). Theorizing the nexus of STEAM practice. Arts Educ. Policy Rev. 119, 88-99.

Przybylla, M., and Romeike, R. (2014). Physical computing and its scope-towards a constructionist computer science curriculum with physical computing. Inform. Educ. 13, 241-254.

Qi, J., Buechley, L., Huang, A. B., Ng, P., Cross, S., and Paradiso, J. A. (2018). "Chibitronics in the wild: engaging new communities in creating technology with paper electronics," in Proceedings of the 2018 CHI Conference on Human Factors in Computing Systems (New York, NY: ACM), 1-11.

Rolling, J. H. Jr. (2008). Rethinking relevance in art education: paradigm shifts and policy problematics in the wake of the information age. Int. J. Educ. Arts 9, $1-18$.

Saldaña, J. (2015). The Coding Manual for Qualitative Researchers. New York, NY: Sage.

Searle, K. A., Fields, D. A., and Kafai, Y. B. (2016). "Is sewing a "girl's sport"? Addressing gender issues in making with electronic textiles," in Makeology: Makers as Learners, eds K. Peppler, E. Halverson, and Y. B. Kafai M (New York, NY: Routledge), 72-84. doi: 10.4324/9781315726496-5

Seidman, I. (2006). Interviewing as Qualitative Research: A Guide for Researchers in Education and the Social Sciences. New York, NY: Teachers college press.

Shaw, M. S., Fields, D. A., and Kafai, Y. B. (2019). Connecting with computer science: electronic textile portfolios as ideational identity resources for high school students. Int. J. Multicult. Educ. 21, 22-41.

Sheridan, K., Halverson, E. R., Litts, B., Brahms, L., Jacobs-Priebe, L., and Owens, T. (2014). Learning in the making: a comparative case study of three makerspaces. Harvard Educ. Rev. 84, 505-531.

Smith, M. (2016). Computer Science for all. Available at: https://www.whitehouse. gov/blog/2016/01/30/computer-science-all (accessed February 4, 2020).

Taylor, B. (2016). Evaluating the benefit of the maker movement in K-12 STEM education. Electron. Int. J. Educ. Arts Sci. 2, 2-22.

Taylor, S. V., and Sobel, D. M. (2011). Culturally Responsive Pedagogy: Teaching Like Our Students' Lives Matter, Vol. 4. Netherlands: Brill.

Vossoughi, S., Hooper, P. K., and Escudé, M. (2016). Making through the lens of culture and power: toward transformative visions for educational equity. Harvard Educ. Rev. 86, 206-232.

Winner, E., Goldstein, T. R., and Vincent-Lancrin, S. (2013). Art for Art's Sake?: The Impact of Arts Education. Paris: OECD publishing.

Yin, R. K. (2009). Case Study Research: Design and Methods, 4th Edn. Thousand Oaks, CA: Sage.

Conflict of Interest: The authors declare that the research was conducted in the absence of any commercial or financial relationships that could be construed as a potential conflict of interest.

Copyright (c) 2020 Lindberg, Fields and Kafai. This is an open-access article distributed under the terms of the Creative Commons Attribution License (CC BY). The use, distribution or reproduction in other forums is permitted, provided the original author(s) and the copyright owner(s) are credited and that the original publication in this journal is cited, in accordance with accepted academic practice. No use, distribution or reproduction is permitted which does not comply with these terms. 